\title{
COM PALAVRAS MINHAS: A TRADUÇÃO DE VERBOS DE ELOCUÇÃO NEUTROS NO CORPUS PARALELO THE ADVENTURES OF HUCKLEBERRY FINN AS AVENTURAS DE HUCK
}

\author{
Daniel Alves de Sousa* \\ Universidade Federal da Paraíba \\ Adriana Silvina Pagano ${ }^{* *}$ \\ Universidade Federal de Minas Gerais
}

\begin{abstract}
Resumo: Este artigo examina o corpus paralelo The Adventures of Huckleberry Finn - As aventuras de Huck, investigando as citações paratáticas e os usos de verbos de elocução em ocorrências de Discurso Direto. O levantamento de dados é realizado com recursos da Linguística de Corpus e a análise de dados, tendo a Gramática Sistêmico-Funcional de Halliday como referencial teórico. O objetivo do trabalho é verificar padrões de escolha de verbos de elocução na textualização original e na (re)textualização de Lobato, sobretudo aqueles relativos aos verbos de
\end{abstract}

\footnotetext{
* Daniel Antonio de Sousa Alves é Professor Adjunto da Universidade Federal da Paraíba (UFPB). Doutor em Estudos da Tradução pela Universidade Federal de Santa Catarina, seus interesses de pesquisa incluem Linguística de Corpus, metodologia de trabalho científico, Linguística Sistêmico-Funcional, coesão textual em textos em relação tradutória. João Pessoa, Paraíba, Brasil. E-mail: daniel@ cchla.ufpb.br.

** Adriana Silvina Pagano é professora titular da Universidade Federal de Minas Gerais (UFMG), onde desenvolve pesquisa sobre (I) conhecimento experto em tradução, (II) modelagem do processo tradutório sob a perspectiva da linguística sistêmico-funcional e (III) abordagens quantitativas da tradução e da produção textual multilíngue. Belo Horizonte, Minas Gerais, Brasil. E-mail: adriana.pagano@gmail.com.
} 
elocução neutros ('say', em inglês e 'dizer', em português). Os resultados mostram uma preferência, na (re)textualização de Lobato, pelo Discurso Direto Livre (em detrimento do Discurso Direto) e uma tendência a escolhas mais diversificadas dos verbos de elocução, não havendo nenhum verbo que cubra mais de $25 \%$ dos casos de representação levantados. Também se observa a neutralidade do verbo 'say' (re)textualizada por meio de verbos que sinalizam a função da fala, no sentido de indicar fornecimento e/ou demanda de informações, ou por verbos que realizam alguma característica adicional da fala ou especificam seu modo.

Palavras-chave: Representação do discurso. Verbos de elocução. Discurso Direto. Monteiro Lobato tradutor.

\title{
IN MY OWN WORDS: THE TRANSLATION OF REPORTING VERBS ON THE PARALLEL CORPUS THE ADVENTURES OF HUCKLEBERRY FINN - AS AVENTURAS DE HUCK
}

\begin{abstract}
This article examines Monteiro Lobato's (re)textualization of Mark Twain's The Adventures of Huckleberry Finn. The analysis focuses on reporting verbs in instances of direct speech. The methodology used for data collection is based on Corpus Linguistics and the analysis built on the hallidayan systemic-functional grammar. The aim of this paper is to explore patterns in the choice of reporting verbs in Twain's and Lobato's textualizations particularly in connection with neutral verbs, such as 'say' in English and 'dizer' in Portuguese. Results show that Lobato's (re) textualization tends to select Free Direct Discourse, (instead of Direct Discourse) and a wider variety of reporting verbs, there being no single verb accounting for more than $25 \%$ of all occurrences of direct discourse examined. The neutral verb 'say' was also observed to have been (re) textualized by reporting verbs that signal speech function, indicating either information giving or demanding, and by verbs that realize an additional feature or specify speech connotation.
\end{abstract}

Keywords: Discourse representation. Reporting verbs. Direct speech. Translator Monteiro Lobato. 


\section{Introdução}

Este artigo investiga a utilização de verbos de elocução em um corpus paralelo bilíngue. A partir das obras The Adventures of Huckleberry Finn - de Mark Twain - e sua (re)textualização $A s$ Aventuras de Huck - por Monteiro Lobato -, são analisadas as ocorrências dos verbos de elocução neutros SAY, em inglês, e DIZER, em português, em projeções paratáticas. A investigação adota uma metodologia baseada na Linguística de Corpus e um arcabouço teórico baseado na Linguística Sistêmico-Funcional de Halliday.

Esta pesquisa se afilia ao campo disciplinar dos Estudos da Tradução e visa contribuir para os estudos que adotam a Linguística Sistêmico-Funcional de Halliday como referencial teórico, estabelecendo interface com a Linguística de Corpus ao agregar subsídios computacionais - por meio da utilização do software WordSmith Tools e de planilhas eletrônicas - nos métodos de investigação adotados.

$\mathrm{O}$ corpus da pesquisa pode ser classificado como de pequenas dimensões, tanto devido ao seu tamanho, quanto devido à metodologia aqui adotada, desenhada para possibilitar o tratamento manual anterior à geração de dados (EHI - Early Human Intervention). Os textos que compõem o corpus são tratados, a partir da proposta de Coulthard (1996), como textualizações de mensagens - escritas por um(a) autor(a) e direcionadas a um determinado público leitor -, sendo a tradução tratada como (re)textualização de uma mensagem que havia sido direcionada a um(a) leitor(a) de uma língua A, para um público leitor de uma língua B. Em nossa pesquisa, a grafia (re) textualização é adotada para sinalizar as fronteiras fluidas entre as diferentes textualizações de mensagens.

Este artigo está composto por quatro seções além desta Introdução, a saber: (i) Revisão teórica, que trata da representação do discurso e suas características, focalizando o discurso direto em citações paratáticas; (ii) Metodologia, em que são apresentadas informações contextuais e críticas sobre os dois romances que compõem o corpus deste artigo e também os passos adotadas para o levantamento 
e análise de dados; por fim, são apresentadas a (iii) Análise dos dados e Discussão e as (iv) "Considerações Finais" deste artigo.

\section{Revisão Teórica}

\section{1 A representação do discurso}

A representação do discurso está relacionada à sinalização da presença de diferentes vozes em um texto. Trata-se de uma meta -representação linguística, contemplada dentro do sistema de projeção na Gramática Sistêmico-Funcional. Nessa abordagem, tanto Halliday e Matthiessen (2004) quanto Matthiessen (2014) definem a noção de projeção como uma relação lógico-semântica entre orações. Segundo os autores, é uma relação na qual se estabelece que uma oração funciona como representação linguística de outra representação (também linguística) - em vez de funcionar como representação linguística de uma experiência não linguística.

O termo representação do discurso é aqui adotado por ser, como afirma Jesus (2004, p.30), "mais amplo e mais adequado às teorias linguísticas e sociais que veem o discurso como uma forma de interpretação e não uma mera reprodução". Além disso, tal termo apresenta uma postura mais abrangente em relação a abordagens normalmente adotadas em gramáticas normativas, por levar em consideração tanto os diferentes tipos de discurso quanto a ideia de que o discurso que antecede a representação nunca é empregado de uma maneira transparente, havendo sempre uma "decisão de se interpretá-lo e representá-lo de uma maneira e não de outra" (FAIRCLOUGH, 1988, p.125).

Dentre os modelos de categorias de representação do discurso, um dos mais acessíveis e divulgados, como afirma Simpson (1993), é o de Leech e Short (1981) cujas categorias são baseadas em “critérios linguísticos explícitos” (SIMPSON, 1993, p. 21). O modelo de Leech e Short (1981) propõe uma escala de interferência na representação que varia desde um grau de grande 
controle do narrador sobre a representação até um grau em que o narrador, aparentemente, não a controla, passando por pontos intermediários. Nesta escala, as seguintes categorias são propostas pelos autores:

I. Representação Narrativa de Ações: narrador indica a ocorrência de um ato anterior, mostrando-o totalmente a partir da sua perspectiva;

II. Representação Narrativa de Atos de Fala: casos em que se dá apenas um mínimo de informação para indicar a ocorrência de um ato de fala anterior, sem que sejam dados mais detalhes sobre tal ato;

III. Discurso Indireto: narrador apresenta um comprometimento apenas com o que foi dito anteriormente, sem apresentar uma grande preocupação em manter as exatas palavras do discurso anterior;

IV. Discurso Indireto Livre: ponto intermediário entre o Discurso Direto e o Discurso Indireto, sendo uma "versão mais livre de uma forma ostensivamente indireta" (LEECH e SHORT, 1981, p. 325) e estando relacionado aos casos em que, apesar de a oração que introduz a representação não ser expressa, a seleção de tempo verbal e de pronomes é semelhante às do discurso indireto;

V. Discurso Direto: narrador apresenta um comprometimento maior tanto com o conteúdo quanto com a forma do que foi anteriormente dito. Para os autores, este discurso é marcado por duas características principais: "a presença de aspas e de uma oração projetante" (LEECH e SHORT, 1981, p. 322);

VI. Discurso Direto Livre: são eliminadas características marcantes do Discurso Direto (como aspas e/ou oração projetante, por exemplo) de modo a produzir uma forma mais livre de discurso; trata-se de casos em que os personagens parecem "falar (...) de maneira mais imediata, sem a intermediação do narrador” (LEECH e SHORT , 1981, p.322). 
Neste trabalho, as formas de representação por Discurso Direto são investigadas, conjugando a proposta de Leech e Short (1981), acima, com a representação do discurso vista pela perspectiva da teoria hallidayana.

A Linguística Sistêmico-Funcional de Halliday considera que a representação do Discurso Direto é realizada por meio de citações e de complexos oracionais, construídos em relação paratática. Essa relação paratática pode ser entendida como uma "relação logicamente (i) simétrica e (ii) transitiva" (MATTHIESSEN, 2014, p. 452), na qual os elementos envolvidos apresentam status semelhante entre si e há alguma liberdade entre as orações - no sentido de que cada uma poderia, por si só, funcionar como um todo. Dois exemplos de Discurso Direto, retirado do corpus, podem ser visto a seguir:

Ex. 1. "Well, hain't he got a father?" says Tom Sawyer.

Ex. 2. - Quem está aí? repetiu ele.

Nos dois exemplos apresentados acima, é possível identificar complexos oracionais formados por duas orações, ambos formados por uma oração projetante e uma oração projetada. Em ambos os casos, a primeira oração pode ser classificada como projetada ("Well, hain't he got a father?" no Ex. 1 e Quem está aí? no Ex. 2) e a segunda oração pode ser classificada como projetante (says Tom Sawyer no Ex. 1 e repetiu ele no Ex. 2)

Para Halliday e Matthiessen (2004) e para Matthiessen (2014), a forma mais simples de projeção da fala é a que ocorre por citações em orações paratáticas. Semino e Short (2004) apontam o Discurso Direto como a forma mais produtiva dentre as ocorrências de representação da fala e afirmam que o uso de formas de citação paratática em textos de ficção serve "a propósitos de dramatização e caracterização que são centrais em romances" (SEMINO e SHORT, 2004, p. 89), gerando um efeito de linguagem mais vívida apresentada ao receptor por simular um suposto evento comunicativo original. 
Dentre as possíveis formas de representação em citações paratáticas, há controvérsia quanto à separação entre as duas formas de discurso direto elencadas no modelo de Leech e Short (1981): o Discurso Direto e o Discurso Direto Livre. Para Leech e Short (1981) as duas categorias são separáveis, ao passo que para Short (1988) e Semino e Short (2004) não há razão para tal separação. A diferença entre as duas categorias é formal: enquanto o Discurso Direto é marcado pelo uso de aspas e pela realização de uma oração projetante, o Discurso Direto Livre se caracteriza por não utilizar os mesmos recursos de forma explícita.

Embora reconheça a existência de tal controvérsia, este trabalho opta por separar as categorias de Discurso Direto e Discurso Direto Livre. Tal decisão se justifica pela visão mais compreensiva que a separação permite sobre controle do narrador acerca dos discursos representados - considerando, para fazer tal afirmação, que no Discurso Direto o controle do narrador é mais marcado (por meio do verbo de elocução) e no Discurso Direto Livre as falas das personagens parecem estar mais livres devido à não sinalização explícita do controle por um narrador.

Tomados neste trabalho como a principal diferença na realização entre o Discurso Direto e o Discurso Direto Livre, os verbos de elocução - que Matthiessen (2014) classifica principalmente dentro da categoria de Processos Verbais - são aqueles que apresentam uma frequência de ocorrência significativa para representar discursos. São Processos que projetam falas, indicam dizeres e contribuem para a criação de narrativas ao colaborar com o estabelecimento de diálogos.

Dentro da proposta de Halliday e Matthiessen (2004), corroborada por Matthiessen (2014), os verbos de elocução podem: 1) ter natureza geral; 2) indicar funções de fala de oferta e demanda de bens e serviços; ou 3) apresentar características adicionais, circunstanciais ou que especificam modos ou conotações. Além disso, para os autores, há ainda uma ampla gama de verbos que pode ter função de elocução, embora prototipicamente realizem outros tipos de Processos. 
Neste trabalho, são analisados os verbos TO SAY - classificados por Halliday e Matthiessen (2004) e por Matthiessen (2014) como membro geral dentre os verbos que funcionam como Processos em Orações Verbais - e o verbo DIZER (tradução mais esperada do verbo TO SAY em português). A razão para tal escolha nesta pesquisa se dá pelo interesse em investigar uma possível tendência de não (re)textualização dos Processos Verbais em romances traduzidos para o português brasileiro (em prol do uso do Discurso Direto Livre), como questiona Assis (2004).

A seção a seguir apresenta o método de investigação adotado neste trabalho, apresentando desde as principais características do corpus investigado até os passos percorridos para a análise.

\section{Metodologia}

\section{1 Sobre o corpus de estudo}

Narrado e protagonizado por Huckleberry Finn, The adventures of Huckleberry Finn apresenta o percurso do garoto Huck, em companhia do escravo Jim pelo sul dos Estados Unidos no século XIX (num período anterior ao fim da escravidão naquele país, que ocorreu em 1863). Primeiramente publicado em 1885, o livro constitui uma importante obra da literatura norte-americana em língua inglesa. Inge (1984) aponta a obra como uma das mais reimpressas, traduzidas e lidas e chega a comparar seu protagonista a outros personagens literários consagrados, como Don Quixote e Hamlet.

A tradução As aventuras de Huck de Monteiro Lobato data de 1934, dentro do período que Pagano (2001a, p. 132) aponta como o "boom da tradução na Argentina e no Brasil". Um fator destacável para a compreensão das escolhas tradutórias feitas por Monteiro Lobato e da sua praxe tradutória diz respeito à proposta do autor em construir textos compreensíveis ao público leitor por ele idealizado, ou, nas palavras de Lajolo (1994, p. 98), a um texto "ao alcance de todos”. Milton (2003, p. 126), por exemplo, destaca a 
fala de Lobato em que afirma abertamente sua proposta de interferir e simplificar suas traduções voltadas para um público infantil:

\begin{abstract}
(...) extirpar a "literatura" de meus livros infantis. A cada revisão nova mato, como quem mata pulgas, todas as literaturas que ainda as estragam. O último submetido a tratamento foram As Fábulas. Como achei pedante e requintado! De lá raspei quase um quilo de "literatura" e mesmo assim ficou alguma...
\end{abstract}

No trecho, é possível notar traços da postura que Pagano (2001b, p. 191) classifica como de "recriação e criatividade em relação a certos aspectos das traduções" por parte de tradutores da época do boom tradutório no Brasil e na Argentina (período que se estende da década de 1930 até 1950). Outros autores - como Vieira (2001) e Schmitz e Caltabiano (2003) - também destacam a concepção de tradução para Lobato: Vieira (2001, p. 148), por exemplo, afirma que, para Lobato, traduzir consiste em reescrever a história, como se ela fosse contada por alguém que a ouviu, mas com suas próprias palavras. Schmitz \& Caltabiano (2003, p. ix) também fazem referências ao estilo de Lobato de traduzir "adaptando, simplificando e alterando os textos".

A proposta de tradução de Lobato - em traduzir simplificando a linguagem -, pode ser identificada até mesmo nos escritos ficcionais do autor. Um exemplo é a fala de Dona Benta - personagem criada pelo autor Lobato - em Dom Quixote das Crianças: na história, ao começar a contar a história de Don Quixote (de Miguel de Cervantes) com linguagem rebuscada, Dona Benta ouve protestos e afirma "em vez de ler vou contar a história com palavras minhas" (Lobato, 1952, p. 12) - proposta bem recebida por sua audiência dentro da história.

No corpus aqui investigado também é possível identificar indícios dessa postura de Lobato em traduzir simplificando e contando a história com suas próprias palavras. Um exemplo disso pode ser 
visto já numa comparação entre as extensões das duas textualizações: enquanto a textualização de Twain apresenta cerca de 115 mil ocorrências (tokens), a (re)textualização de Lobato apresenta cerca de 86 mil (um número 25,2\% menor que o Twain). Outro indício pode ser visto nas escolhas tradutórias de Lobato em suas representações do discurso - ponto que motiva este estudo e será mais bem desenvolvido na quarta seção deste artigo (quando da análise de dados e discussão). A seguir, são apresentadas as etapas metodológicas adotadas para a realização desta pesquisa.

\subsection{Etapas Metodológicas}

O primeiro passo para a análise empreendida neste trabalho é a identificação das representações do discurso (em projeções paratáticas) realizadas no corpus desta pesquisa. Tal identificação é realizada com base na característica de tais projeções em serem marcadas graficamente - como apontam Leech e Short (1981, p. 322) e Cunha (1971, p. 450). Para tanto, analisam-se as textualizações e identificam-se as sinalizações gráficas empregadas por Twain e por Lobato para sinalizar as projeções paratáticas em suas textualizações.

As sinalizações gráficas são marcadas nos textos por meio de etiquetas, escritas entre parênteses angulares $\langle>$, de forma a facilitar o levantamento das linhas de concordância a serem analisadas.

Utilizando o concordanceador do software WordSmith Tools, são levantadas as linhas de concordância relacionadas às etiquetas que inseridas no corpus ( $<$ Asp $>,</$ Asp $>$ e $<$ Trav $>$, definidas segundo as características de cada textualização, como será apontado na próxima seção). As linhas de concordância são copiadas e organizadas em planilhas eletrônicas para facilitar os procedimentos de análise.

Os passos seguintes a serem empreendidos na análise são realizados concomitantemente: a separação entre os casos de Discurso Direto e os casos de Discurso Direto Livre e a identificação dos 
verbos de elocução responsáveis pela projeção do discurso (nos casos de Discurso Direto). O objetivo de tal identificação é a quantificação dos verbos de elocução empregados em cada textualização e a visualização global dos verbos em cada uma delas. Para fins de sistematização, a identificação dos verbos de elocução é feita não pelas formas como os verbos são utilizados no corpus, mas lexemas que os representam - dessa forma, usos de 'falaram', 'falava', 'falarão', etc., por exemplo, são anotados sob o lexema FALAR.

Por fim, separados os casos de Discurso Direto e Discurso Direto Livre e identificados os verbos utilizados na representação do discurso, buscam-se analisar as representações do discurso, investigando as variedades lexicais dos verbos de elocução e possíveis padrões de utilização de tais verbos. A seção a seguir apresenta os resultados da investigação aqui realizada.

\section{Análise dos dados e Discussão}

Como apontado na seção anterior, o primeiro passo realizado nesta investigação é a identificação dos sinais gráficos empregados para indicar citações paratáticas. Analisando-se os textos individualmente - e respeitando as características de cada um -, nota-se que na textualização de Twain são empregadas aspas para sinalizar a representação de discursos e na (re)textualização de Lobato são travessões.

Constatadas as características das textualizações, marcam-se por meio das etiquetas $<$ Asp $>,</$ Asp $>$ as aspas e por meio da etiqueta $\langle$ Trav $\rangle$ - as ocorrências de projeção paratática do discurso. Os casos a seguir exemplificam os usos dessas marcações por meio de etiquetas:

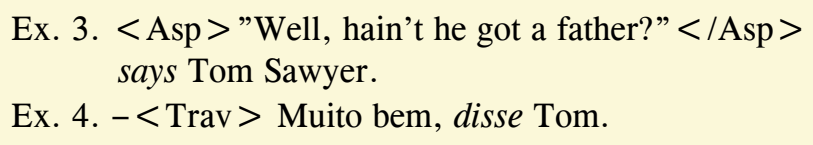


Os Ex. 3 e Ex. 4, acima, mostram duas ocorrências de Discurso Direto retiradas respectivamente de The adventures of Huckleberry Finn e As aventuras de Huck. Os exemplos mostram os verbos de elocução neutros SAY e DIZER (marcadas em itálico para facilitar a identificação) projetando as orações 'Well, hain't he got a father?' e 'Muito bem', além de mostrar as etiquetas $<$ Asp $>$, $</ A s p>$ e $<$ Trav $>$, empregadas para facilitar o levantamento das citações diretas no texto por meio do concordanciador do WordSmith Tools.

Como apontado na seção anterior, por meio da ferramenta Concord, do software WordSmith Tools, é realizado o levantamento das ocorrências de representação do discurso em citações paratáticas no corpus desta pesquisa. O resultado são 1.442 ocorrências na textualização de Twain e 1.318 ocorrências na (re)textualização de Lobato. Interessante notar, em relação a esses números, que, embora a (re)textualização de Lobato seja 25,2\% menor que a textualização de Twain (como apontado na seção 3.1), o número de citações paratáticas nas duas textualizações é próximo: na (re) textualização de Lobato há apenas 124 ocorrências a menos que na textualização de Twain - em termos percentuais a redução no número de projeções corresponde a $8,60 \%$.

A diferença no número de representações do discurso (comprada aos tamanhos das duas textualizações) pode ser vista como um indício de uma predileção de Lobato por (re)textualizar diálogos em detrimento de trechos mais narrativos do texto, uma vez que a redução na extensão do romance como um todo não guarda proporção com a redução no número de projeções. Esse indício condiz com a observação de Vieira (1998) que - utilizando como referência cartas de Lobato endereçadas a Godofredo Rangel - aponta a preferência pela utilização de diálogos como uma característica da práxis tradutória de Lobato.

Seguindo os passos delineados no método de pesquisa aqui empregado, as 1.442 ocorrências de representações do discurso em citações paratáticas na textualização de Twain e as 1.318 na (re) textualização de Lobato são classificadas, visando-se a separação 
entre os casos de Discurso Direto e os de Discurso Direto Livre. O Gráfico, a seguir, mostra os resultados dessa classificação:

Gráfico 1 - Citações paratáticas no corpus, divididas entre casos de Discurso Direto e Discurso Direto Livre

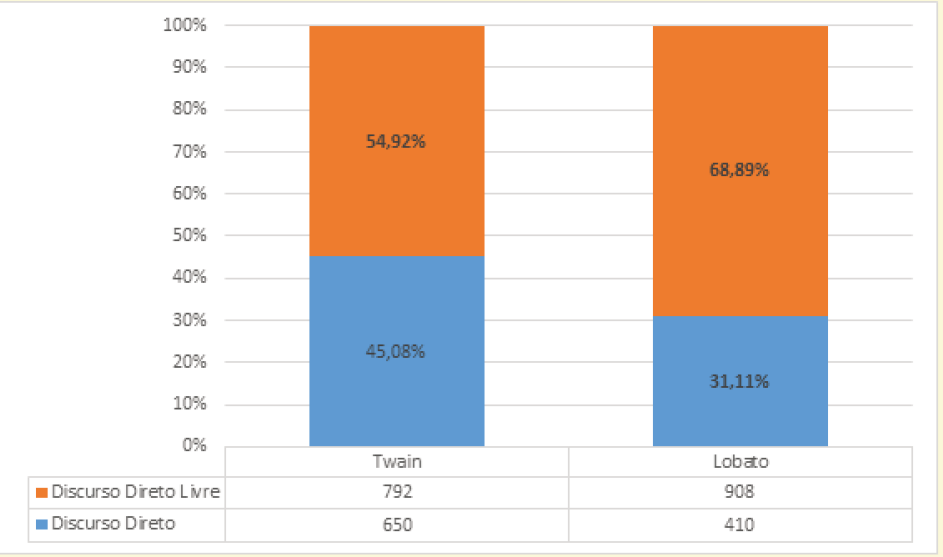

O Gráfico1, acima, mostra o total de ocorrências de representações do discurso em citações paratáticas levantado nesta pesquisa, fazendo a distinção entre casos de uso de Discurso Direto e de Discurso Direto Livre. Na coluna à esquerda, podem ser vistos os resultados relativos à textualização de Twain: 792 dos casos levantados (o que corresponde a $54,92 \%$ do total) são classificados como Discurso Direto Livre e 650 (45,08\% do total) são classificados como Discurso Direto. Já na (re)textualização de Lobato, 908 dos casos levantados (68,89\% do total) são classificados como Discurso Direto Livre e 410 (31,11\% do total) são classificados como Discurso Direto. A seguir, são apresentados exemplos de cada um dos casos:

Ex. 5. He tore it up, and says: <Asp $>$ "I'll give you something better - I'll give you a cowhide. " $</$ Asp $>$ 
Ex. 6. $-<$ Trav > E você? Tem pêlo nos braços e no peito Jim? indaguei.

Ex. 7. $<$ Asp $>$ "Ransomed? What's that? " $</$ Asp $>$ $<$ Asp $>$ "I don't know. But that's what they do. I've seen it in books; and so of course that's what we've got to do. " $</$ Asp $>$

$<$ Asp $>$ "But how can we do it if we don't know what it is? " $</$ Asp $>$

Ex. 8. $-<$ Trav > Então, Jim, você só tem comido framboesas?

$-<$ Trav $>$ Não descobri nada mais.

$-<$ Trav $>$ Há quanto tempo está aqui?

Os exemplos acima mostram casos de Discurso Direto e de Discurso Direto Livre retirados do corpus. Nos dois primeiros casos, Ex. 5 e Ex. 6, são apresentadas citações paratáticas projetadas, respectivamente, pelos processos 'says' e 'indaguei' (em itálico nos exemplos para facilitar a identificação). Nos outros dois casos, Ex. 7 e Ex. 8, são apresentados casos de Discurso Direto Livre - em que as partes envolvidas na interação parecem dialogar livremente, sem o controle de um narrador.

É possível dizer que a preferência pelo emprego do Discurso Direto Livre tem impacto para a construção das textualizações. Considerando - como apontam Short (1988, p. 71) e Simpson (1993, p. 22) - que a não utilização explícita de verbos de elocução (marca do Discurso Direto Livre) confere às representações do discurso o mais alto grau de liberdade. Dessa forma, o uso predominante de Discurso Direto Livre cria, nas textualizações, a impressão de que as personagens falam por si próprias, menos sujeitas ao controle de um narrador.

O fato de a predileção pelo Discurso Direto Livre ser ainda mais marcada nas escolhas feitas por Lobato em sua (re)textualização (em comparação com as escolhas de Twain) condiz com as observações de Vieira (1998, p.22), que aponta o uso do diálogo como uma característica da práxis tradutória de Lobato, afirmando que, 
por meio do diálogo "a história não é contada por um único narrador", não havendo uma única "voz adulta, unidirecional contando os fatos, passando suas ideias como verdades incontestáveis".

Após a separação entre os casos de Discurso Direto Livre e os de Discurso Direto, o passo seguinte adotado nesta pesquisa é a identificação dos verbos de elocução utilizados na representação do discurso (nos casos de Discurso Direto). Seguindo os passos delineados no método de pesquisa, os verbos de elocução são organizados lematicamente em uma Tabela. O resultado dessa organização pode ser visualizado nas Tabelas 1 e 2, a seguir. Inicialmente, é apresentada a Tabela X, que organiza os resultados dos verbos de elocução utilizados nas representações do discurso na textualização de Twain:

\begin{tabular}{|l|l|l|}
\hline $\begin{array}{l}\text { Verbo de elocução } \\
\text { (LEMAS) }\end{array}$ & Número de ocorrências & Valor percentual \\
\hline SAY & 589 & $90,62 \%$ \\
\hline SING OUT & 27 & $4,15 \%$ \\
\hline SHOUT & 7 & $1,08 \%$ \\
\hline TELL & 3 & $0,46 \%$ \\
\hline Outros & 24 & $3,69 \%$ \\
\hline TOTAL & 650 & $100,00 \%$ \\
\hline
\end{tabular}

Tabela 1 - Verbos de elocução utilizados nas representações do discurso na textualização de Twain.

A Tabela 1 elenca os verbos de elocução empregados nos casos de Discurso Direto na textualização de Twain, agrupando-os lematicamente. Por delimitação de espaço, estão apresentados na tabela apenas os casos com mais de três (03) ocorrências - uma versão integral da tabela está disponibilizada nos anexos deste artigo.

A textualização de Twain utiliza uma variedade reduzida de verbos de elocução: 24 verbos de elocução diferentes são empregados para projetar os 650 casos analisados (reiterando que se trata 
aqui de casos de Discurso Direto). Destes verbos, o verbo neutro SAY é o mais empregado (correspondendo a $90,62 \%$ do total), como mostra a tabela. Outros verbos, como SING OUT $(4,15 \%)$ e SHOUT $(1,08 \%)$, apresentam algum destaque, mas são utilizados numa proporção bem menor se comparados à utilização do verbo SAY. A seguir são apresentados exemplos de representação do discurso retirados da textualização de Twain:

Ex. 9. He tore it up, and says:

$<$ Asp $>$ "I'll give you something better - I'll give you a cowhide. " $</$ Asp $>$

Ex. 10. Somebody sings out: $<$ Asp $>$ "Boggs! “ $<1$ Asp >

Os Ex. 9 e Ex. 10, acima, mostram dois casos de Discurso Direto retirados do corpus desta pesquisa. No primeiro, Ex. 9, a fala "I'll give you something better - I'll give you a cowhide." é projetada pelo processo verbal "says" (em itálico no exemplo para facilitar a identificação), já no segundo, Ex. 10, a fala "Boggs!" é projetada pelo processo verbal "sings out".

A Tabela 2, a seguir, organiza os verbos de elocução utilizados para projetar discursos na (re)textualização de Lobato:

\begin{tabular}{|l|l|l|}
\hline $\begin{array}{l}\text { Verbo de elocução } \\
\text { (LEMAS) }\end{array}$ & Número de ocorrências & Valor percentual \\
\hline DIZER & 98 & $23,90 \%$ \\
\hline EXCLAMAR & 33 & $8,05 \%$ \\
\hline INDAGAR & 33 & $8,05 \%$ \\
\hline PERGUNTAR & 28 & $6,83 \%$ \\
\hline RESPONDER & 24 & $5,85 \%$ \\
\hline FALAR & 17 & $4,15 \%$ \\
\hline REDARGUIR & 13 & $3,17 \%$ \\
\hline INQUIRIR & 12 & $2,93 \%$ \\
\hline
\end{tabular}




\begin{tabular}{|l|l|l|}
\hline GRITAR & 10 & $2,44 \%$ \\
\hline TORNAR & 9 & $2,20 \%$ \\
\hline ACRESCENTAR & 8 & $1,95 \%$ \\
\hline COMEÇAR & 7 & $1,71 \%$ \\
\hline CONTINUAR & 7 & $1,71 \%$ \\
\hline Outros & 111 & $27,08 \%$ \\
\hline TOTAL & 410 & $100,00 \%$ \\
\hline
\end{tabular}

Tabela 2 - Verbos de elocução utilizados nas representações do discurso na (re) textualização de Lobato.

A Tabela 2 elenca os verbos de elocução empregados nos casos de Discurso Direto na (re)textualização de Lobato. Também por delimitação de espaço, constam da tabela apenas os casos que reúnem mais de sete (07) ocorrências - versão integral da tabela está disponibilizada nos anexos deste artigo.

A Tabela 2 mostra o emprego de uma variedade consideravelmente maior de verbos de elocução na (re)textualização de Lobato em comparação à variedade empregada por Twain. A (re)textualização de Lobato emprega 80 diferentes verbos de elocução nas 410 linhas de discurso direto analisadas. Há proeminência no uso do verbo DIZER (que corresponde a $23,90 \%$ do total de verbos de elocução empregados), mas seu uso não é tão destacado quanto o do verbo SAY na textualização de Twain. Outros verbos bastante empregados são EXCLAMAR (8,05\%), INDAGAR (8,05\%), PERGUNTAR (6,83\%), RESPONDER (5,85\%), e FALAR (4,15\%). A seguir são apresentados exemplos de representação do discurso retirados da (re)textualização de Lobato:

Ex. 11. $-<$ Trav $>$ Huck tem pai, sim, volveu Tom

Ex. 12. $-<$ Trav $>\mathrm{O}$ que você precisa é de um bom chicote, rosnou ele rasgando a estampa. 
Os Ex. 11 e Ex. 12, acima, mostram dois casos de representação do discurso retirados da (re)textualização de Lobato. No primeiro, Ex. 11, a fala "Huck tem pai, sim" é projetada pelo processo verbal 'volveu' (em itálico no exemplo para facilitar a identificação), já no segundo, Ex. 12, a fala "O que você precisa é de um bom chicote" é projetada pelo processo verbal 'rosnou' (também em itálico).

Analisando-se os verbos de elocução empregados na (re)textualização de Lobato, é possível identificar o que parece ser uma tentativa de seleção de um leque mais amplo de verbos que realizam os Processos Verbais. Um indício que aponta para isto é o elevado número de verbos de elocução empregados, já que a (re)textualização de Lobato emprega 80 diferentes verbos de elocução, contra 24 da textualização de Twain e, em Lobato, nenhum verbo cobrir mais do que $25 \%$ dos casos.

Dentre os verbos de elocução mais empregados na (re)textualização de Lobato - e excetuando-se o verbo DIZER para fazer tal afirmação -, possuem destaque verbos INDAGAR (8,05\%), PERGUNTAR $(6,83 \%)$ e RESPONDER $(5,85 \%)$. Trata-se de verbos que indicam a cronologia do discurso, indicando características da situação de fala, do papel do narrador e que nomeiam os atos e fala em questão. $\mathrm{O}$ uso desses verbos de elocução indica uma tentativa de explicitar a interação entre os personagens por meio dos verbos de elocução. Enquanto na textualização de Twain, os personagens mais 'dizem', na (re)textualização, eles têm papéis claramente delimitados na interação entre si, fazendo perguntas e respondendo-as - o que torna explícita a situação da fala nas representações de discursos.

A seguir, são mostrados exemplos das escolhas de Lobato ao (re)textualizar o verbo de elocução neutro SAY, envolvendo verbos de elocução não neutros:

Ex. 13. Miss Watson's big nigger, named Jim, was setting in the kitchen door; we could see him pretty clear, because there was a light behind 
him. He got up and stretched his neck out about a minute, listening. Then he says:

$<$ Asp > "Who dah?" </Asp >

Ex. 14. Jim, o negrão de Miss Watson, estava sentado à porta da cozinha. Vimo-lo perfeitamente, pois que havia luz acesa lá dentro.

- < Trav > Quem anda aí? gritou ele.

Ex. 15. Pretty soon Jim says:

$<$ Asp $>$ "Say, who is you? Whar is you? Dog my cats ef I didn' hear sumf'n. Well, I know what I's gwyne to do: I's gwyne to set down here and listen tell I hears it agin." </Asp >

Ex. 16. Ao cabo de certo tempo Jim rompeu o silêncio. $-<$ Trav > Quem está aí? repetiu ele. É alguém, bem sei. Meus ouvidos não me enganam e tenho a certeza de ter ouvido bulha de gente. Não responde? Pois vou ficar aqui até o fim, e quero ver.

O quatro exemplos acima mostram casos em que o verbo de elocução neutro SAY da textualização de Twain é (re)textualizado empregando verbos de elocução não-neutros. Nos Ex. 13 e Ex. 14, "he says" é (re)textualizado por Lobato como "gritou ele" e nos Ex. 15 e Ex. 16, o 'Jim says' é (re)textualizado como "repetiu ele". No primeiro par de exemplos (Ex. 13 e Ex. 14), a escolha de Lobato acrescenta à representação características adicionais modo de fala, já no segundo par (Ex. 15 e Ex. 16), a escolha de Lobato acrescenta à representação características especifica a funções de fala (em situação de demanda de informação). Esses movimentos de acrescentar informações, optando pela utilização de verbos de elocução não neutros em situações em que a textualização opta pelo uso de verbos de elocução neutros são o que aqui se denomina como uma tentativa de seleção de um leque mais amplo de verbos que realizam os Processos Verbais.

A seção a seguir retoma os principais pontos deste artigo e apresenta sugestões de futuros desenvolvimentos para este trabalho. 


\section{Considerações Finais}

Este trabalho se propôs a discutir a (re)textualização dos verbos de elocução (utilizados em casos de discurso direto) para o português do Brasil, num corpus paralelo bilíngue, composto pelos romances The adventures of Huckleberry Finn e As aventuras de Huck. Investigaram-se aqui os casos de representação do discurso em citações paratáticas.

Em relação à representação do discurso em citações paratáticas, a investigação aqui feita aponta é favorecida pela distinção entre as categorias Discurso Direto e Discurso Direto Livre. Como levantado ao longo do texto, embora haja opiniões divergentes quanto a tal separação, nos dados analisados nesta pesquisa, a separação entre as categorias permite uma compreensão mais abrangente sobre diferentes construções textuais, considerando o grau de influência de um narrador sobre o discurso projetado.

Quanto à metodologia empregada, este trabalho busca respeitar características discursivas próprias de cada um dos romances que compõem o seu corpus de estudo ao buscar qual seria a anotação mais indicada para cada um dos textos. Apesar de se tratar de uma opção mais trabalhosa, ao lidar com cada texto individualmente, a preocupação em trabalhar com as textualizações respeitando suas características próprias se mostra mais adequada - por permitir um levantamento adequado das representações do discurso e a identificação dos verbos de elocução empregados.

Em relação à (re)textualização de Lobato, verifica-se uma redução da extensão do texto - uma vez notado que a (re)textualização de Lobato é cerca de $25,2 \%$ menor do que a textualização de Twain. Também é possível notar uma predileção pela utilização de diálogos em detrimento de trechos narrativos: a (re)textualização de Lobato parece não apresentar uma redução de igual magnitude em relação ao número de representações do discurso em citações paratáticas, já que a diferença entre o número de linhas de concordância (de citações paratáticas) levantadas na (re)textualização de Lobato é de $8,60 \%$. 
Tais posturas podem indicar a adoção de uma preferência pela tradução de diálogos em relação à tradução de trechos mais narrativos do texto, o que reflete o ideal explicitado de Lobato em produzir textos mais dramatizados e de mais fácil compreensão por parte do público infantil.

Quanto aos verbos de elocução empregados na (re)textualização de Lobato, parece haver tendência de diversificação dos verbos de elocução, não havendo, na (re)textualização de Lobato, um único verbo que cubra mais de $25 \%$ dos casos de representação levantados. Em relação ao impacto das escolhas de Lobato para (re) textualizar o verbo neutro SAY, foi observado que a neutralidade do verbo 'say' foi (re)textualizada por meio de verbos que ou bem sinalizam a função da fala, no sentido de indicar fornecimento e/ ou demanda de informações, ou por verbos que indicam alguma característica adicional da fala ou especificam ou modo da mesma. O impacto deste tipo de escolhas precisa ser mais bem investigado, contemplando-se a (re)textualização de outros verbos, além dos neutros, de forma a verificar se as observações em nível de dados quantitativos poderiam ser interpretadas como tendo um impacto cumulativo em termos qualitativos.

Por fim, quanto à investigação relacionada ao questionamento de Assis (2004) - sobre uma possível tendência de não (re) textualização dos verbos de elocução neutros nas traduções para o português brasileiro -, este trabalho aponta para um uso mais elevado do Discurso Direto Livre na (re)textualização, mas os números não são suficientes para a adoção de um posicionamento conclusivo quanto a existência de tal tendência - o que leva à sugestão de que outras investigações sejam empreendidas para se testar a pergunta de pesquisa. 


\section{Referências}

ASSIS, R. C. A transitividade na representação de Sethe no corpus paralelo BelovedAmada. 2004. Dissertação (mestrado) - Universidade Federal de Minas Gerais.

COULTHARD, M. On Analysing and Evaluating Written Text. In COULTHARD, M (Ed.). Advances in Written Text Analysis. London and New York: Routledge, 1996:1-11.

CUNHA, Celso. Gramática do português contemporâneo: de acordo com a Nomenclatura Gramatical Brasileira. 2. ed. Belo Horizonte: B.Alvares, 1971. 509 p.

FAIRCLHOUGH, Norman. Discourse Representation in Media Discourse. Sociolinguistics, n. 17, 1988:125-139.

HALLIDAY, M.A.K. e MATTHIESSEN, Christian. An Introduction to Functional Grammar. 3 ed. London: Hodder Arnold. 2004.

INGE, M Thomas. Introduction. In INGE, M Thomas (Ed.). Huck Finn among the critics. Washington DC: Forum Series, 1984:v-ix.

JESUS, S. Representação do discurso e tradução padrões de textualização em corpora paralelo e comparável. 2004. Dissertação (mestrado) - Universidade Federal de Minas Gerais.

LAJOLO, Marisa. Do mundo da leitura para a leitura do mundo. 2. ed. São Paulo: 1994. 112p.

LEECH, G. e SHORT, M.. Style in fiction. London \& New York: Longman, 1981. p. 318-351.

LOBATO, M. D. Quixote das crianças. 3 ed. São Paulo: Editora Brasiliense, 1952.

MATTHIESSEN, C.M.I.M. Halliday's Introduction to Functional Grammar. London and New York: Routledge, 2014.

MILTON, J.. Monteiro Lobato and translation: "Um país se faz com homens e livros". DELTA, 2003, vol.19, no.spe, p.117-132. ISSN 0102-4450. 
PAGANO, A. As pesquisas historiográficas em tradução. IN: PAGANO, Adriana. Metodologias de pesquisa em tradução. FALE-UFMG, Belo Horizonte, 2001a, p. 117-146.

PAGANO, A. "An Item Called Books: Translations and Publishers" Collections in the Editorial Booms in Argentina and Brazil from 1930 to 1950'. IN: Milton, John, ed. Emerging Views on Translation History in Brazil, special issue of Crop 6. Universidade de São Paulo, Brasil: 2001b, 171-194.

SEMINO, E. and SHORT, M. Corpus Stylistics: Speech, writing and thought presentation in a corpus of English writing. London and New York: Routledge, 2004.

SCHMITZ, J. e CALTABIANO, M.A. Apresentação. DELTA, 2003, vol.19, no.spe, p. VII-XI. ISSN 0102-4450.

WORDSMITH TOOLS. (Scott, M.). 4.0. Oxford: Oxford University Press, 2005.

SHORT, M. "Speech Presentation, the novel and the press". IN: VAN PEER, Willie (Ed.) the taming of the text: explorations in language, literature and culture. London \& New York: Routledge, 1988: 61-81.

SIMPSON, P. Language, ideology and point of view. London \& New York: Routledge, 1993:11-45.

TWAIN, M. The Adventures of Huckleberry Finn. Harmondsworth: Penguin Books, 1968. Primeira publicação 1885.

TWAIN. M. As aventuras de Huck. Tradução de Monteiro Lobato. São Paulo - SP: Editora Brasiliense, 1973. Primeira publicação 1934. Original em inglês.

VIEIRA, A. "Monteiro Lobato Translator". IN: Milton, John, ed. Emerging Views on Translation History in Brazil, special issue of Crop 6. Universidade de São Paulo, Brasil: 2001, 143-169.

Recebido em: 23/07/2015 Aceito em: 05/09/2015 


\section{Anexos}

\begin{tabular}{|c|c|c|}
\hline $\begin{array}{l}\text { Verbo de elocução } \\
\text { (LEMAS) }\end{array}$ & $\begin{array}{l}\text { Número de } \\
\text { ocorrências }\end{array}$ & $\begin{array}{l}\text { Valor } \\
\text { percentual }\end{array}$ \\
\hline SAY & 589 & $90,62 \%$ \\
\hline SING OUT & 27 & $4,15 \%$ \\
\hline SHOUT & 7 & $1,08 \%$ \\
\hline TELL & 3 & $0,46 \%$ \\
\hline HOLLER & 2 & $0,31 \%$ \\
\hline KEEP SAYING & 2 & $0,31 \%$ \\
\hline SPEAK UP AND SAY & 2 & $0,31 \%$ \\
\hline WHISPER & 2 & $0,31 \%$ \\
\hline $\begin{array}{l}\text { ANSWER BACK AND } \\
\text { SAY }\end{array}$ & 1 & $0,15 \%$ \\
\hline BLETHER OUT & 1 & $0,15 \%$ \\
\hline CRY AND SAY & 1 & $0,15 \%$ \\
\hline DRAWL OUT & 1 & $0,15 \%$ \\
\hline FETCH OUT & 1 & $0,15 \%$ \\
\hline GASP OUT & 1 & $0,15 \%$ \\
\hline $\begin{array}{l}\text { GROAN, CRY AND } \\
\text { SAY }\end{array}$ & 1 & $0,15 \%$ \\
\hline LISTEN & 1 & $0,15 \%$ \\
\hline MAKE A SIGN & 1 & $0,15 \%$ \\
\hline NOD & 1 & $0,15 \%$ \\
\hline RIP OUT & 1 & $0,15 \%$ \\
\hline RIP OUT AND SAY & 1 & $0,15 \%$ \\
\hline
\end{tabular}




\begin{tabular}{l|l|l}
\hline RUN ON & 1 & $0,15 \%$ \\
\hline START & 1 & $0,15 \%$ \\
\hline WRITE & 1 & $0,15 \%$ \\
\hline YELL & 1 & $0,15 \%$ \\
\hline Total & 650 & $100,00 \%$ \\
\hline
\end{tabular}

Tabela 1 - Tabela completa (Verbos de elocução empregados na textualização de Twain)

\begin{tabular}{l|l|l}
\hline $\begin{array}{l}\text { Verbo de elocução } \\
\text { (LEMAS) }\end{array}$ & $\begin{array}{l}\text { Número de } \\
\text { ocorrências }\end{array}$ & $\begin{array}{l}\text { Valor } \\
\text { percentual }\end{array}$ \\
\hline DIZER & 98 & $23,90 \%$ \\
\hline EXCLAMAR & 33 & $8,05 \%$ \\
\hline INDAGAR & 33 & $8,05 \%$ \\
\hline PERGUNTAR & 28 & $6,83 \%$ \\
\hline RESPONDER & 24 & $5,85 \%$ \\
\hline FALAR & 17 & $4,15 \%$ \\
\hline REDARGUIR & 13 & $3,17 \%$ \\
\hline INQUIRIR & 12 & $2,93 \%$ \\
\hline GRITAR & 10 & $2,44 \%$ \\
\hline TORNAR & 9 & $2,20 \%$ \\
\hline ACRESCENTAR & 8 & $1,95 \%$ \\
\hline COMEÇAR & 7 & $1,71 \%$ \\
\hline CONTINUAR & 7 & $1,71 \%$ \\
\hline BRADAR & 5 & $1,22 \%$ \\
\hline MURMURAR & 5 & $1,22 \%$ \\
\hline & &
\end{tabular}




\begin{tabular}{|c|c|c|}
\hline $\begin{array}{l}\text { Verbo de elocução } \\
\text { (LEMAS) }\end{array}$ & $\begin{array}{l}\text { Número de } \\
\text { ocorrências }\end{array}$ & $\begin{array}{l}\text { Valor } \\
\text { percentual }\end{array}$ \\
\hline ATALHAR & 4 & $0,98 \%$ \\
\hline REPETIR & 4 & $0,98 \%$ \\
\hline RETRUCAR & 4 & $0,98 \%$ \\
\hline BERRAR & 3 & $0,73 \%$ \\
\hline COMENTAR & 3 & $0,73 \%$ \\
\hline CONCLUIR & 3 & $0,73 \%$ \\
\hline CONTAR & 3 & $0,73 \%$ \\
\hline ORDENAR & 3 & $0,73 \%$ \\
\hline ROSNAR & 3 & $0,73 \%$ \\
\hline SUGERIR & 3 & $0,73 \%$ \\
\hline VOLVER & 3 & $0,73 \%$ \\
\hline AFIRMAR & 2 & $0,49 \%$ \\
\hline CHAMAR & 2 & $0,49 \%$ \\
\hline CONTESTAR & 2 & $0,49 \%$ \\
\hline CONTRAVIR & 2 & $0,49 \%$ \\
\hline INTERPELAR & 2 & $0,49 \%$ \\
\hline INTERROMPER & 2 & $0,49 \%$ \\
\hline LEMBRAR & 2 & $0,49 \%$ \\
\hline OUVIR & 2 & $0,49 \%$ \\
\hline PROTESTAR & 2 & $0,49 \%$ \\
\hline REPLICAR & 2 & $0,49 \%$ \\
\hline SUSSURRAR & 2 & $0,49 \%$ \\
\hline APLAUDIR & 1 & $0,24 \%$ \\
\hline AVISAR & 1 & $0,24 \%$ \\
\hline
\end{tabular}




\begin{tabular}{l|l|l}
\hline $\begin{array}{l}\text { Verbo de elocução } \\
\text { (LEMAS) }\end{array}$ & $\begin{array}{l}\text { Número de } \\
\text { ocorrências }\end{array}$ & $\begin{array}{l}\text { Valor } \\
\text { percentual }\end{array}$ \\
\hline $\begin{array}{l}\text { BATER AOS } \\
\text { OUVIDOS }\end{array}$ & 1 & $0,24 \%$ \\
\hline CONCORDAR & 1 & $0,24 \%$ \\
\hline CONSOLAR & 1 & $0,24 \%$ \\
\hline CORTAR & 1 & $0,24 \%$ \\
\hline COTEJAR & 1 & $0,24 \%$ \\
\hline DECLARAR & 1 & $0,24 \%$ \\
\hline DIRIGIR-SE & 1 & $0,24 \%$ \\
\hline EMENDAR & 1 & $0,24 \%$ \\
\hline ENTOAR & 1 & $0,24 \%$ \\
\hline ESCAPAR & 1 & $0,24 \%$ \\
\hline ESCUTAR & 1 & $0,24 \%$ \\
\hline EXCULPAR & 1 & $0,24 \%$ \\
\hline EXPLICAR & 1 & $0,24 \%$ \\
\hline FAZER & 1 & $0,24 \%$ \\
\hline FOI A RESPOSTA & 1 & $0,24 \%$ \\
\hline IMPLORAR & 1 & $0,24 \%$ \\
\hline INSISTIR & 1 & $0,24 \%$ \\
\hline INTERROGAR & 1 & $0,24 \%$ \\
\hline LAMENTAR & 1 & $0,24 \%$ \\
\hline MONOLOGAR & 1 & $0,24 \%$ \\
\hline OBJETAR & 1 & $0,24 \%$ \\
\hline PEDIR & 1 & $0,24 \%$ \\
\hline & 1 &
\end{tabular}




\begin{tabular}{|c|c|c|}
\hline $\begin{array}{l}\text { Verbo de elocução } \\
\text { (LEMAS) }\end{array}$ & $\begin{array}{l}\text { Número de } \\
\text { ocorrências }\end{array}$ & $\begin{array}{l}\text { Valor } \\
\text { percentual }\end{array}$ \\
\hline PRAGUEJAR & 1 & $0,24 \%$ \\
\hline PRONTIFICAR & 1 & $0,24 \%$ \\
\hline PROSSEGUIR & 1 & $0,24 \%$ \\
\hline QUERER SABER & 1 & $0,24 \%$ \\
\hline REDAQUIR & 1 & $0,24 \%$ \\
\hline $\begin{array}{l}\text { REPETIR O } \\
\text { PEDIDO }\end{array}$ & 1 & $0,24 \%$ \\
\hline RETOMAR A PALAVRA & 1 & $0,24 \%$ \\
\hline RUGIR & 1 & $0,24 \%$ \\
\hline SOAR & 1 & $0,24 \%$ \\
\hline SOLUÇAR & 1 & $0,24 \%$ \\
\hline SUSPIRAR & 1 & $0,24 \%$ \\
\hline TARTAMUDEAR & 1 & $0,24 \%$ \\
\hline TERMINAR & 1 & $0,24 \%$ \\
\hline ACALMAR & 1 & $0,24 \%$ \\
\hline ULULAR & 1 & $0,24 \%$ \\
\hline ADVERTIR & 1 & $0,24 \%$ \\
\hline URRAR & 1 & $0,24 \%$ \\
\hline APARTEAR & 1 & $0,24 \%$ \\
\hline VOCIFERAR & 1 & $0,24 \%$ \\
\hline Total & 410 & $100,00 \%$ \\
\hline
\end{tabular}

Tabela 2 - Tabela completa (Verbos de elocução empregados na (re)textualização de Lobato) 